\title{
Maturity changes in Norwegian spring-spawning herring Clupea harengus: compensatory or evolutionary responses?
}

\author{
Georg H. Engelhard ${ }^{1,2, *}$, Mikko Heino ${ }^{1,3}$ \\ ${ }^{1}$ Institute of Marine Research, PO Box 1870 Nordnes, 5817 Bergen, Norway \\ ${ }^{2}$ CEFAS Lowestoft Laboratory, Pakefield Road, Lowestoft NR33 0HT, UK \\ ${ }^{3}$ Adaptive Dynamics Network, International Institute for Applied Systems Analysis, 2361 Laxenburg, Austria
}

\begin{abstract}
The stock of Norwegian spring-spawning herring Clupea harengus collapsed to a state of commercial extinction in the 1960s, probably due to both overexploitation and unfavourable climatic conditions. Since the 1980s, the stock has fully recovered. Following the collapse, the fish matured at much earlier ages and somewhat larger sizes than previously. Currently, age and size at $50 \%$ maturity have only to some extent returned to pre-collapse levels. Two non-exclusive hypotheses that may account for the maturity changes are (1) the 'compensatory response' hypothesis, predicting that reduced stock size resulting from exploitation leads to faster growth and hence earlier maturity as a phenotypically plastic response to environmental change; and (2) the 'evolutionary response' hypothesis, predicting that intensive exploitation causes selection for early maturation, since few late-maturing phenotypes survive until first spawning. Trends in length-at-age suggest a strong compensatory response, but leave the possibility of evolutionary change unaddressed. In order to disentangle phenotypic and possible genetic changes in maturation, we examined the reaction norm for age and size at maturation to see if any changes had occurred. This reaction norm describes the probabilities of maturing at each relevant age and size. We found small but statistically significant changes in maturation reaction norms; these changes were restricted to 2 out of 6 of the maturation ages. This confirms that growth-related phenotypic plasticity has largely been responsible for the documented changes in maturity, and suggests at most a weak evolutionary response. This is in line with theoretical expectations from the dominating fishing pattern, where pure schools of only mature or only early immature fish were targeted, rather than a fishery on both immature and mature fish simultaneously, as has been the case in stocks of cod Gadus morhua and plaice Pleuronectes platessa, where significant evolutionary responses have been found.
\end{abstract}

KEY WORDS: Fisheries-induced change - Evolution - Phenotypic plasticity - Reaction norm · Maturation · Growth rates

Resale or republication not permitted without written consent of the publisher

\section{INTRODUCTION}

A range of commercially exploited fish stocks throughout the world has declined substantially over the past decades (e.g. Christensen et al. 2003, Myers \& Worm 2003). These declines have often coincided with marked changes in the ages and sizes at which fish commence reproducing (e.g. Haug \& Tjemsland 1986, Jørgensen 1990, Rijnsdorp 1993, Trippel 1995, O'Brien 1999, Bromley 2000). In most cases, the fish now mature at earlier ages and smaller sizes than they did some decades ago. Both age and size at maturation are closely linked to lifetime reproductive success (Stearns 1992, Bernardo 1993), and therefore to stock productivity. It is thus of high relevance to assess the possible causes of maturity changes in exploited fish stocks (Marshall et al. 1998, Murawski et al. 2001).

At least 2 non-exclusive hypotheses may account for maturity changes (Borisov 1978, Law \& Grey 1989, Browman 2000, Law 2000, Heino \& Godø 2002, Heino 
et al. 2002a). Firstly, the 'compensatory response' hypothesis predicts that earlier maturation is a phenotypically plastic response to a reduction in stock size induced by exploitation. The resultant relaxation of resource competition causes compensatory growth; with higher growth rates, the fish attain the size required for maturation more quickly. Secondly, the 'evolutionary response' hypothesis predicts that earlier maturation is due to a genetic change in maturation characteristics, arising from the selective effects of fishing. With strongly increased mortality, the expected number of spawnings becomes very small for late-maturing individuals, and natural selection will favour early-maturing phenotypes, even if these have lower age-specific fertility. In later generations, individuals with a genetic make-up for maturation at earlier ages (or at smaller sizes) will thus become more and more numerous compared to late-maturing fish. It should be noted that fishing mortality often exceeds natural mortality by a factor of 2 to 3 , and that for many exploited stocks, removal of fish after recruitment to the fisheries often runs as high as $50 \%$ each year (Stokes \& Law 2000).
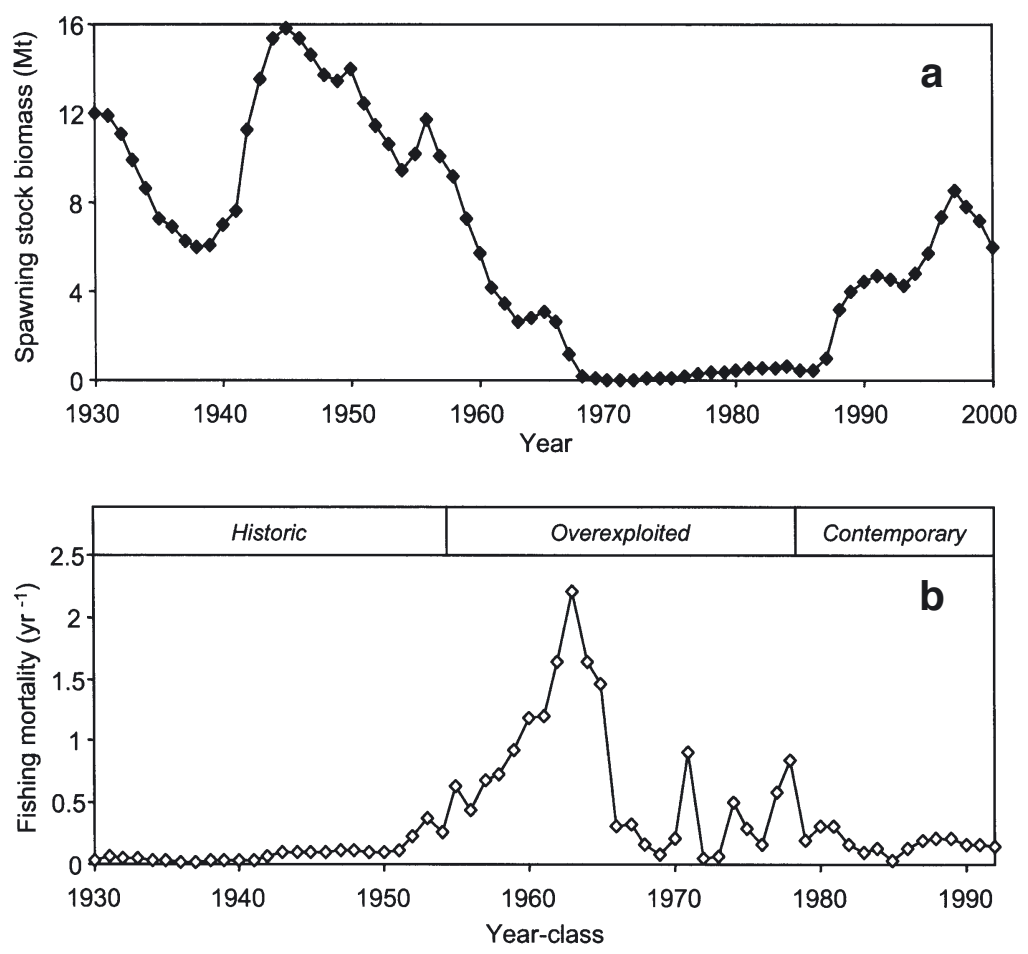

Fig. 1. Clupea harengus. Long-term variation in (a) spawning stock biomass over the years 1930 to 2000, and (b) fishing mortality (averaged for the ages 5 to 13) for the year-classes 1930 to 1992 (from ICES 2002). Spawning stock biomass is shown per year, and fishing mortality per year-class. Definitions of the historic, overexploited, and contemporary series of year-classes as used in this paper are indicated in (b)
These 2 scenarios have important implications for fisheries management. If earlier maturation is strictly a phenotypically plastic response to low stock abundance, then a reduction in exploitation causing the stock to increase will readily reverse the changes. By contrast, if an evolutionary response has occurred, the changes will be hard to reverse, and are likely to persist over a (very) long time-span (Law 2000). There is now increasing evidence that over periods of decades, evolutionary changes in maturation traits have indeed occurred in exploited fish stocks, including North Sea plaice Pleuronectes platessa (Rijnsdorp 1993, Grift et al. 2003) and several stocks of Atlantic cod Gadus morhua (Heino et al. 2002c, Barot et al. in press). Controlled selection experiments have moreover confirmed the potential of harvesting-induced selection to cause rapid evolutionary change in yield-related traits (Conover \& Munch 2002).

Norwegian spring-spawning herring Clupea harengus, distributed in the Norwegian and Barents Seas, is the world's largest herring stock. The stock declined throughout the 1950s and 1960s and collapsed close to commercial extinction in the late 1960s (Fig. 1). Until the early 1980s, it remained at extremely low levels. Following the recruitment of a number of strong year-classes, the stock is now considered to be fully recovered (Toresen \& Østvedt 2000). Climatic factors are thought to underlie the abundance fluctuations in herring (Corten 2001), and unfavourable climate probably contributed to the decline of Norwegian springspawning herring (Toresen \& Østvedt 2000). There is no doubt, however, that overexploitation of both adult and juvenile herring strongly contributed to the depletion (Dragesund \& Ulltang 1978, Toresen \& Jakobsson 2002). Fishing mortality was extremely high during the 1960s, and despite strict fishing regulations following the collapse, the fishing mortality remained at a high level for much of the 1970s and 1980s, due to the very low stock size (Fig. 1). In fact, most of the year-classes 1955 to 1978 suffered fishing mortality rates of 0.5 to $4 \mathrm{yr}^{-1}$ at some or at most ages, compared to an estimated natural mortality of $0.15 \mathrm{yr}^{-1}$ (ICES 2002).

Strong changes in growth and maturity coincided with the collapse (Toresen 1990a,b, Engelhard \& Heino 2004). The average growth rates were considerably higher in the collapsed period than in the pre-collapse period (Toresen 1990a, Holst \& Slotte 1998), but have decreased again after the stock's recovery. This suggests that compensatory growth occurred in the period of reduced stock biomass (Toresen 

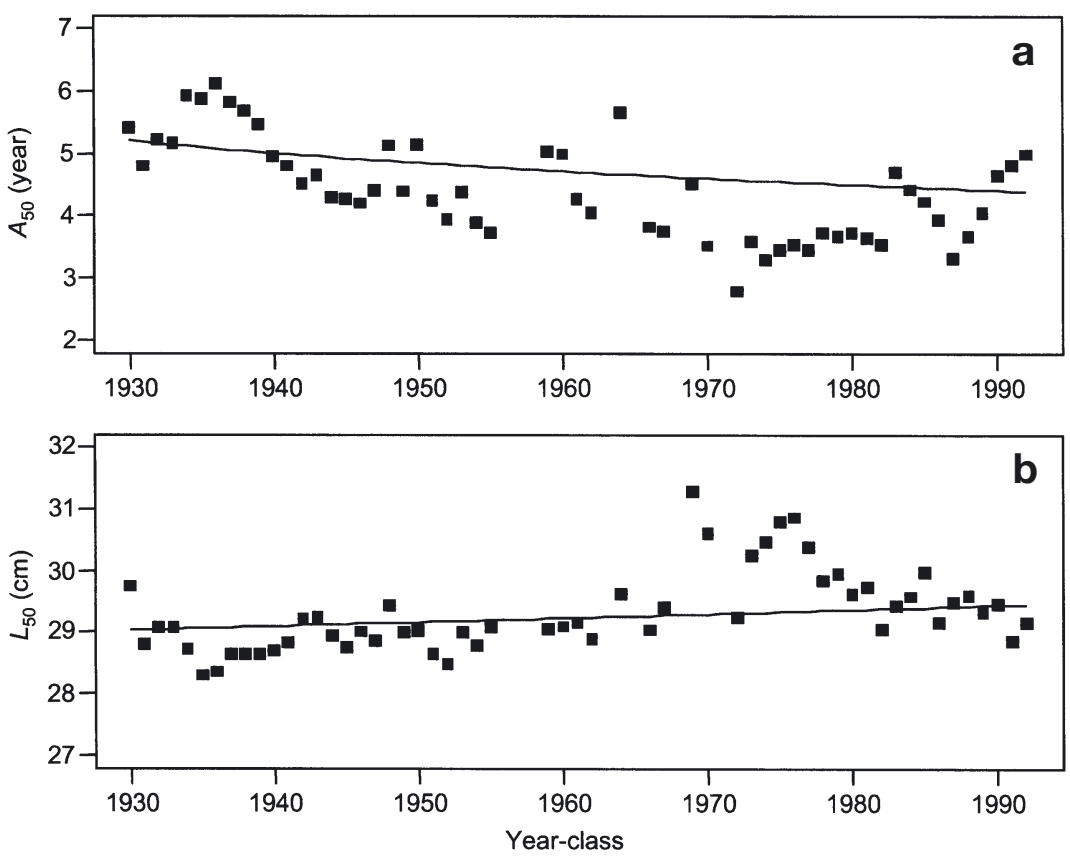

Fig. 2. Clupea harengus. (a) Age at $50 \%$ maturity $\left(A_{50}\right)$, and (b) length at $50 \%$ maturity $\left(L_{50}\right)$ for the year-classes 1930 to 1992 . Trend lines show longterm decrease in $A_{50}$ and increase in $L_{50}$; both trends are statistically significant. In 9 year-classes, sample sizes were insufficient to compute reliable $A_{50}$ and $L_{50}$ estimates. Data and methods are as in Engelhard \& Heino (2004), but the estimates are corrected for different mortality rates among mature and immature individuals following Jørgensen's (1990) procedure as described in 'Materials and methods'

1990a, Engelhard \& Heino 2004). In the collapsed period, the fish matured at considerably earlier ages and somewhat larger sizes than previously (Fig. 2): the age at $50 \%$ maturity decreased from ( $~ 5$ to 6$)$ to $\sim 4 \mathrm{yr}$ and the length at $50 \%$ maturity increased from $\sim 29$ to $\sim 30 \mathrm{~cm}$. The maturity characteristics in the current period of renewed high stock abundance have only to some extent returned to pre-collapse levels (Fig. 2). An intriguing question is, can the maturity changes be entirely attributed to phenotypically plastic responses to abundance-related changes in environment, as predicted by the compensatory response hypothesis, or are these, in addition, due to fishery-induced changes in the genetic composition of the stock, as predicted by the evolutionary response hypothesis?

This paper aims at the disentanglement of phenotypically plastic and genetic changes in maturation for Norwegian spring-spawning herring. We approach this challenging task by an analysis of reaction norms for age and size at maturation (Stearns \& Koella 1986, Heino et al. 2002a,b). The tendency of an immature individual to mature under given conditions is a genetically determined individual charac- teristic. Reaction norms for age and size at maturation describe this tendency, given that an individual has reached a certain age and size. This conditioning allows one to separate the description of the inherent maturation tendency from the descriptions of growth and survival. The latter 2 determine the likelihood of reaching a certain age and size. Being strongly influenced by the environment, they are the major sources of plastic variability in maturation (Heino et al. 2002a,b). In contrast to maturation reaction norms, the traditional measures of maturation, maturity-at-age and maturity-at-length, are directly influenced not only by inherent changes in maturation tendency, but also by variations in growth and survival.

Can change in maturation reaction norms be taken as evidence of evolutionary change in maturation tendency, given that maturation tendency must be under genetic control? The caveat is that reaction norms for age and size at maturation are not only influenced by genetic changes in maturation, but also by unaccounted sources of phenotypic plasticity: factors such as variations in body condition may introduce noise into reaction norms. Evolutionary changes in maturation, on the other hand, are expected to be manifested as longterm trends in maturation reaction norms. However, in absence of experimental controls, the possibility that some change in the environment is causing such a trend can never be discounted. Nevertheless, the reaction norm method allows for dealing with the major source of plasticity in maturation, i.e. variations in growth. For applications of the maturation reaction norm method to important fish stocks we refer to Grift et al. (2003) and Barot et al. (in press).

The paper builds on our earlier work, which provided support of the compensatory response hypothesis for the Norwegian spring-spawning herring stock, but did not test the evolutionary response hypothesis (Engelhard \& Heino 2004). The latter hypothesis is examined here (1) through a comparison of maturation reaction norms between year-classes that lived either before (1930 to 1954) or after (1979 to 1992) those that suffered very intensive exploitation, i.e. a comparison of the 'historic' with the 'contemporary' reaction norm, and (2) by an analysis of long-term trends in reaction norms throughout the period 1930 to 1992. 


\section{MATERIALS AND METHODS}

Sampling. The study is based on mature individuals of Norwegian spring-spawning herring sampled by the Institute of Marine Research (Bergen) during January to March of 1935 to 2000. The fish were caught at or near the spawning grounds situated along the Norwegian west coast between 58 to $69^{\circ} \mathrm{N}$. Samples of 100 to 200 herring were collected from drift-net, beach-seine, purse-seine, and trawl catches, caught by commercial or research vessels. These samples are considered to be representative of the spawning stock of Norwegian spring-spawning herring (e.g. Toresen 1990a, Holst 1996).

Individual measurements. For each fish, body length, weight, sex, and maturity stage were determined. The age was determined by counting the annual growth layers in the scale (Runnström 1936). For most fish collected before 1974, the age at maturation (equivalent here to age at first spawning) was also determined based on the annual growth layers in the scale (see Runnström 1936, Engelhard et al. 2003). The visual determination of age at maturation was discontinued in 1974. Therefore, in order to examine trends in maturity over the entire time-series before and after stock collapse, we used discriminant analysis to predict age at maturation from data on the widths of annual growth layers in the scales (Engelhard et al. 2003). The prediction parameters were established with the historical collection of scales where both growth layer measurements and directly observed age at maturation were available $(\mathrm{n}=45386)$. Discriminant analysis was then used to predict age at maturation for 116479 herring with growth layer measurements, sampled throughout the period of 1935 to 2000.

Maturation reaction norms. We computed probabilistic reaction norms for age and length at maturation, hereafter referred to as maturation reaction norms (Heino et al. 2002a,b). These reaction norms describe the probability of immature individuals to mature during a given season, conditional to having obtained a certain age and length. Direct estimation of probabilistic maturation reaction norms requires observations on the lengths of both immature and newly matured individuals (Heino et al. 2002a). We do not have direct observations on length of immature herring, but such information can be reconstructed utilising back-calculated lengths-at-age and knowledge on age at maturation of each fish. A similar reconstruction method has been developed and validated by Heino et al. (2002b).

Reaction norms were analysed separately for Ages 3 to 8 yr because by Age 9, all herring in this stock are mature (Runnström 1936, Engelhard et al. 2003). The analyses were carried out for most year-classes of Norwegian spring-spawning herring from 1930 to 1992, except where data availability was very limited; combinations of age and year-class with $<4$ immature or $<4$ maturing individuals were excluded. This was the case for many of the weak year-classes preceding and following stock collapse. Data were similarly scarce for many year-classes for late maturation ages (6 to 8 yr). The sample sizes are summarised in Table 1.

The procedure for statistical analysis of maturation reaction norms for Norwegian spring-spawning herring involves 2 steps where the necessary data are compiled, and 3 steps of statistical modelling. The procedure is presented below:

1. Obtaining size distributions of immature and maturing individuals: Length frequency distributions of immature fish were obtained by back-calculations of length-at-age based on scale growth layers and total body length of fish sampled as adults. Length frequency distributions of maturing individuals were either obtained directly (for fish sampled as first-time spawners), or from back-calculations of length-at-age (for fish sampled as repeat spawners). Length backcalculations were based on length at catch $\left(L_{\mathrm{c}}\right)$, total

Table 1. Clupea harengus. Sample sizes for immature (I) and maturing, first-time spawning (M) Norwegian spring-spawning herring at Ages 3 to 8. Sample sizes are shown per decade of year-classes and for the historic (Hist.) and contemporary (Cont.) series of year-classes

\begin{tabular}{|c|c|c|c|c|c|c|c|c|c|c|c|c|}
\hline \multirow{2}{*}{ Year-classes } & \multicolumn{2}{|c|}{ Age 3} & \multicolumn{2}{|c|}{ Age 4} & \multicolumn{2}{|c|}{ Age 5} & \multicolumn{2}{|c|}{ Age 6} & \multicolumn{2}{|c|}{ Age 7} & \multicolumn{2}{|c|}{ Age 8} \\
\hline & I & $\mathrm{M}$ & I & M & I & $\mathrm{M}$ & I & M & I & M & I & $\mathrm{M}$ \\
\hline 1930-1939 & 12756 & 55 & 14291 & 729 & 10390 & 2483 & 4320 & 4165 & 910 & 2091 & 0 & 0 \\
\hline $1940-1949$ & 7935 & 54 & 6920 & 1755 & 2455 & 3670 & 362 & 1703 & 85 & 186 & 0 & 0 \\
\hline 1950-1959 & 17111 & 116 & 12949 & 1719 & 6585 & 3354 & 2229 & 3074 & 1509 & 615 & 378 & 414 \\
\hline 1960-1969 & 2208 & 10 & 5236 & 2004 & 2656 & 3030 & 398 & 2922 & 30 & 496 & 0 & 0 \\
\hline $1970-1979$ & 11350 & 903 & 2146 & 9096 & 74 & 1609 & 0 & 0 & 0 & 0 & 0 & 0 \\
\hline 1980-1989 & 22640 & 432 & 16509 & 5056 & 4510 & 16078 & 253 & 5037 & 16 & 232 & 0 & 0 \\
\hline 1990-1992 & 13138 & 29 & 18549 & 861 & 7637 & 6796 & 1175 & 4203 & 16 & 617 & 0 & 0 \\
\hline Hist., 1930-1954 & 32187 & 221 & 29072 & 3716 & 16273 & 7773 & 6603 & 6554 & 2426 & 2520 & 368 & 295 \\
\hline Cont., 1979-1992 & 37993 & 557 & 35542 & 9022 & 12159 & 23182 & 1428 & 9240 & 32 & 849 & 0 & 0 \\
\hline
\end{tabular}


scale radius $\left(S_{\mathrm{c}}\right)$, and the radius of the scale at Age $i$ $\left(S_{i}\right)$. The following formula was used to back-calculate length $L_{i}$ at the earlier Age $i$ (scale-proportional length back-calculation as recommended by Francis 1990):

$$
L_{i}=-r+\frac{\left(L_{\mathrm{C}}+r\right) S_{i}}{S_{\mathrm{C}}}
$$

where $r=a / b$, with $a$ and $b$ being the intercept and regression coefficient, respectively, of the linear regression of total scale radius on body length $(a=$ $-0.949 \mathrm{~mm}, b=0.0209$ ).

2. Adjusting size distributions according to the maturity ogive: Due to unequal sampling effort and mortality between years, the proportion of immature and maturing individuals in the length distributions obtained in Step 1 was not representative of the actual proportions in the population as a whole, the maturing types typically being over-sampled. However, it is possible to calculate the unbiased proportions of immature and maturing individuals at age for a given year-class through information on maturity-at-age using the following formula (Heino et al. 2002b):

$$
m(a)=\frac{o(a)-o(a-1)}{1-o(a-1)}
$$

where $m(a)$ is the fraction of maturing among immature and maturing individuals at Age $a$, and $o(a)$ is the maturity ogive describing maturity at Age a (i.e. the fraction of mature individuals among the total number of mature and immature individuals at Age a). At each combination of age and year-class, the maturing individuals were then subsampled randomly by a factor $k_{\text {, }}$ such that

$$
k=\frac{n^{*}{ }_{m}}{n_{m}}=\frac{n_{i} m(a)}{n_{m}[1-m(a)]}
$$

where $n^{*}{ }_{m}$ is the corrected number of maturing individuals, and $n_{m}$ and $n_{i}$ are the sampled numbers of maturing and immature individuals, respectively.

The maturity ogives were computed using Gulland's (1964) method, which is based on the relative abundances of first-time and repeat spawners. However, one major assumption in the method - equal survival for immature and mature fish of a given age - was probably violated here, as the majority of Norwegian spring-spawning herring fisheries have traditionally targeted mature herring. This causes a bias, which, if the mortality difference is known, can be corrected as described by Jørgensen (1990). We applied this method, assuming that natural mortality was equal for mature and immature fish of the same age. For estimating fishing mortality rates $(F)$, we assumed that immature fish suffered the mean $F$ for 2 and 3 yr old Norwegian spring-spawning herring during a given year (on average, $>99 \%$ of the fish are still immature at
Age 3), and that mature fish suffered the mean $F$ for the Ages 7 to 12 in that year (on average, $>94 \%$ of individuals have reached maturity at Age 7 ). The F-values were obtained from the official stock assessment (ICES 2002).

3. Estimation of the maturation reaction norm: At each of the relevant maturation ages, the maturation reaction norm - or probability of maturing $p$ as a function of length $L$ - was estimated by means of logistic regression, with maturation as the binary response variable (maturing vs remaining immature):

$$
\operatorname{logit}(p) \approx c_{0}+c_{1} L
$$

where $C_{0}$ and $C_{1}$ are the model parameters to be estimated, and where the logit link function is given by $\operatorname{logit}(p)=\log _{\mathrm{e}}[p /(1-p)]$. The maturation reaction norm is here described, first, by the reaction norm midpoints $\left(L_{P 50}\right)$, which at each maturation age describe the length where the probability of maturing reaches $50 \%$ (Heino et al. 2002a). Second, the reaction norm width describes how rapidly the probability of maturing increases with length; width is defined as the interval between the lengths that lead to maturation probabilities of 10 and $90 \%$ ( $L_{P 10}$ and $L_{P 90}$, respectively).

4. Analysis of differences between reaction norms before and after overexploitation period: To examine for possible impacts of the overfishing on the stock, we calculated a 'historic' maturation reaction norm based on the year-classes 1930 to 1954, which lived before the period of overexploitation; and a 'contemporary' reaction norm representing the yearclasses 1979 to 1992, which lived after the overexploitation period. We analysed for differences between the historic and contemporary reaction norms by extending the logistic regression model given in Eq. (4) as follows:

$$
\operatorname{logit}(p) \approx c_{0}+c_{1} L+C_{2} P+C_{3} L \times P
$$

where the factor $P$ examines for differences in reaction norm midpoints between the periods before or after overexploitation, and the interaction $L \times P$ examines for differences in the reaction norm width between the 2 periods. Analyses were again carried out separately for the different maturation ages.

5. Analysis of trends in maturation reaction norms: We examined for overall temporal trends in reaction norms over the entire study period 1930 to 1992 by including year-class $Y$ as a variate in the model given in Eq. (4):

$$
\operatorname{logit}(p) \approx c_{0}+c_{1} L+c_{2} Y+c_{3} L \times Y
$$

where the variate $Y$ allows for the analysis of a change in reaction norm midpoints over time, and the interaction $L \times Y$ examines for a change in the reaction norm width over time. 

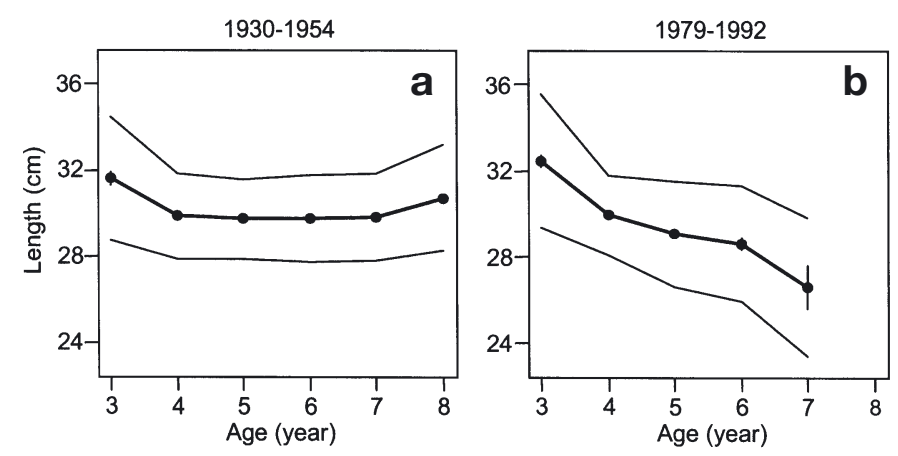

Fig. 3. Clupea harengus. Average maturation reaction norm for (a) the year-classes 1930 to 1954 representing the period before overexploitation, and (b) the year-classes 1979 to 1992 representing the period after overexploitation (Eq. 5). The thick line connects reaction norm midpoints $\left(L_{P 50}\right)$ indicating the length-at-age where the probability of maturing equals $50 \%$. The lower and upper thin lines show the reaction norm width and indicate the length where the probability of maturing equals 10 and $90 \%$, respectively

\section{RESULTS}

\section{'Historic' and 'contemporary' maturation reaction norms}

Fig. 3a shows the 'historic' maturation reaction norm for the year-classes 1930 to 1954 representing the period before overexploitation, when the Norwegian spring-spawning herring stock was still at very high levels and exposed to only moderate fishing pressure. For comparison, Fig. 3b shows the 'contemporary' reaction norm for the year-classes 1979 to 1992, which all lived after the period of very high fishing pressure (represented by the intervening yearclasses 1955 to 1978). In the contemporary period, few fish remained immature past Age 7, and no fish past Age 8 (Table 1); due to the resultant lack of data on immature fish, the contemporary reaction norm is inaccurately known for Age 7 and unknown for Age 8.

The historic and, to a lesser extent, the contemporary reaction norm show a generally horizontal slope for ages of 4 and over (except for Age 7 in the contemporary reaction norm, based on fish from only 3 year-classes). The reaction norm midpoints $L_{P 50}$, describing the length at which the probability of maturing equals $50 \%$, are similar ( 29 to $30 \mathrm{~cm})$ for these ages. The reaction norm width is moreover relatively con- stant for these ages; the distances between $L_{P 10}$ and $L_{P 90}$ are $\sim 4$ to $5 \mathrm{~cm}$. This implies that for ages of 4 and over, the probability of maturing at a given length is relatively age-independent. For Age 3, however, the reaction norm midpoint is considerably higher $(\sim 32 \mathrm{~cm})$ and the width broader $(\sim 6 \mathrm{~cm})$ in both periods, implying that at this early age fish have lower and more variable tendencies to mature than their sizes would suggest.

Some changes in the shape of the reaction norm appear to have occurred between the 2 periods: the contemporary reaction norm shows a more decreasing trend with age and broader width than the historic reaction norm. Statistical analyses (Table 2) revealed a significant decrease in reaction norm midpoints at Ages 5 (by $0.67 \mathrm{~cm}$ ) and 6 (by $1.13 \mathrm{~cm}$ ) between the 2 periods, and an increase in the reaction norm width at the same ages (by 1.22 and $1.34 \mathrm{~cm}$ ). The magnitude of these changes, however, was small; the current reaction norm midpoints are only $2.2 \%$ (Age 5) and $3.8 \%$ (Age 6) less than the values for the historic period. For other ages there was no statistical evidence of a change in the maturation reaction norm.

\section{Trends in maturation reaction norms}

Logistic regression analyses of trends in maturation reaction norms (Eq. 4) over the entire study period confirm the finding of quantitatively small but statistically significant changes at certain maturation ages. For the various maturation ages, Fig. 4 shows reaction norm midpoints and widths with sufficient data for the year-

Table 2. Clupea harengus. Maturation reaction norms in Norwegian springspawning herring: comparison between 'historic' year-classes that lived before (1930 to 1954) and 'contemporary' year-classes that lived after (1979 to 1992) the period of very high fishing mortality rates. Analyses were carried out separately for the different maturation ages with logistic regression models (Eq. 5). $t$ and $\mathrm{p}$ refer to Student's $t$-test statistic and the associated probability, with values of $\mathrm{p}<0.05$ (in bold) indicating significant change. Sample sizes are given in Table 1

\begin{tabular}{|c|c|c|c|c|c|c|}
\hline Age $(y r)$ & Hist. & Cont. & Change & $\%$ & $t$ & $\mathrm{p}$ \\
\hline \multicolumn{7}{|c|}{ Reaction norm midpoint $\left(L_{P 50} \pm \mathrm{SE}\right)(\mathrm{cm})$} \\
\hline 3 & $31.8 \pm 0.30$ & $32.4 \pm 0.30$ & +0.68 & +2.1 & 0.62 & 0.536 \\
\hline 4 & $29.9 \pm 0.04$ & $29.9 \pm 0.09$ & +0.07 & +0.2 & -1.24 & 0.217 \\
\hline 5 & $29.7 \pm 0.06$ & $29.1 \pm 0.09$ & -0.67 & -2.2 & 3.76 & $<0.001$ \\
\hline 6 & $29.8 \pm 0.06$ & $28.6 \pm 0.25$ & -1.13 & -3.8 & 3.07 & 0.002 \\
\hline 7 & $29.8 \pm 0.10$ & $26.6 \pm 0.99$ & -3.20 & -10.7 & 1.30 & 0.195 \\
\hline 8 & $30.7 \pm 0.11$ & - & & & & \\
\hline \multicolumn{7}{|c|}{ Reaction norm width $\left(L_{P 90}-L_{P 10}\right)(\mathrm{cm})$} \\
\hline 3 & 5.7 & 6.1 & +0.40 & +6.9 & -0.79 & 0.429 \\
\hline 4 & 3.9 & 3.7 & -0.30 & -7.5 & 1.17 & 0.241 \\
\hline 5 & 3.6 & 4.9 & +1.2 & +33 & -3.51 & $<0.001$ \\
\hline 6 & 4.0 & 5.4 & +1.3 & +33 & -2.81 & 0.005 \\
\hline 7 & 4.1 & 6.4 & +2.4 & +58 & -1.14 & 0.258 \\
\hline 8 & 4.9 & - & & & & \\
\hline
\end{tabular}



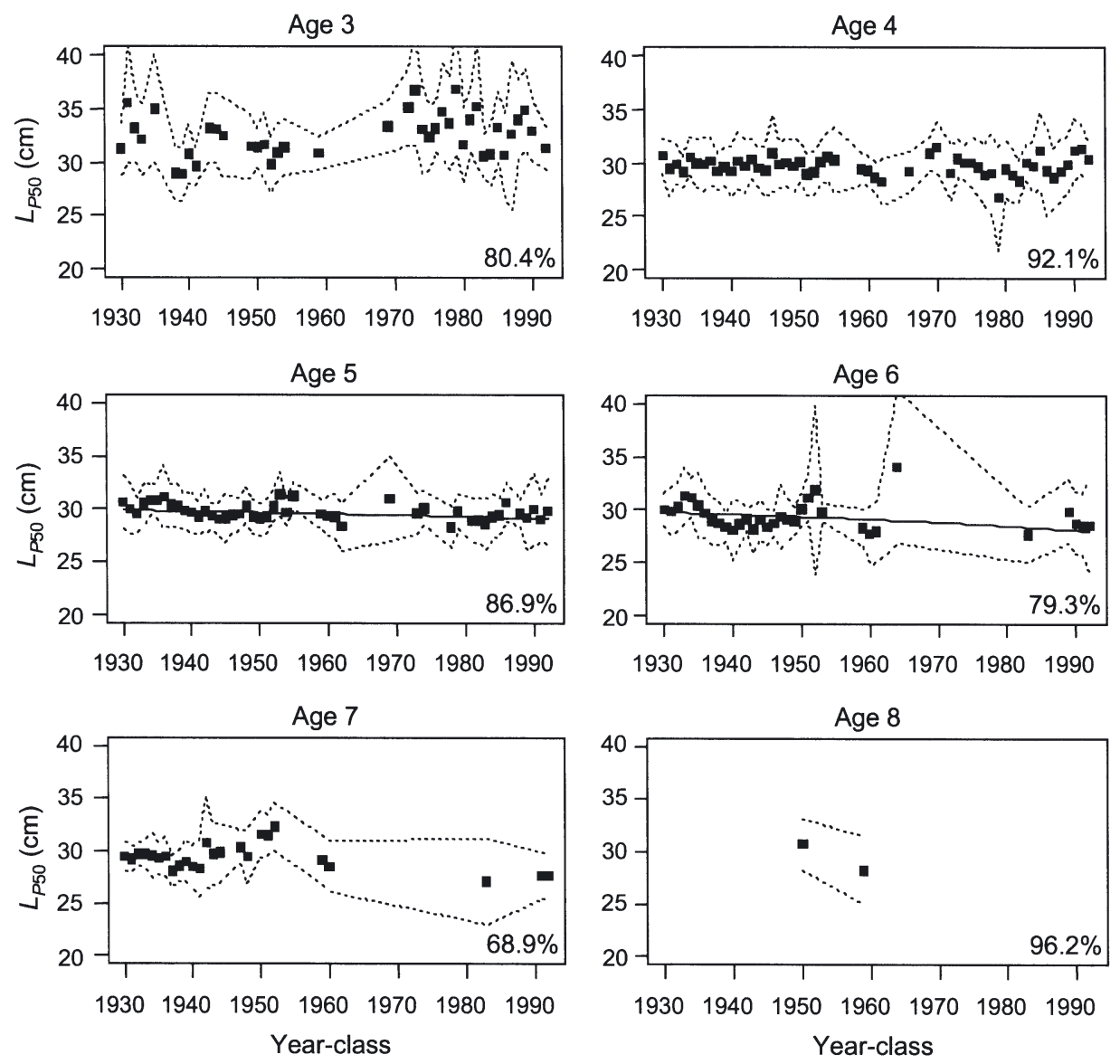

Fig. 4. Clupea harengus. Reaction norm midpoints $\left(L_{P 50}\right)$ for the year-classes 1930 to 1992 at maturation Ages 3 to 8 (Eq. 4 ). For some combinations of age and year-class, sample sizes were insufficient. Lower and upper dotted lines show the reaction norm width and indicate the length-at-age where the probability of maturing equals 10 and $90 \%$, respectively. For Ages 5 and 6 , logistic regressions (Eq. 6) indicated significant temporal trends in reaction norms; solid lines show the model-predicted trends. Percentages indicate the proportion of deviance explained by the model (Eq. 6)

classes 1930 to 1992. Note that at higher maturation ages, data on immature fish were more limited (Table 1), which resulted in reaction norm analyses being restricted to smaller numbers of year-classes.

There were significant trends in reaction norms for Ages 5 (midpoint: $\mathrm{p}<0.001$, width: $\mathrm{p}<0.001$ ) and 6 (midpoint: $\mathrm{p}<0.001$, width: $\mathrm{p}<0.001$ ). However, the magnitude of the changes was small: from 1930 to 1992, the midpoints for Ages 5 and 6 were predicted to have decreased by 2.8 and $3.3 \%$ of the original value, respectively. Trends for Age 7 were suggestive but insignificant (midpoint: $\mathrm{p}=0.067$; width: $\mathrm{p}=0.072$ ). There was no evidence of temporal trends for other ages (midpoint: $\mathrm{p}>0.42$; width: $\mathrm{p}>0.50$ ).

\section{DISCUSSION}

This study serves to better understand the marked changes in maturity that have occurred over the past decades in the Norwegian spring-spawning herring stock (Toresen 1990a,b, Toresen \& Østvedt 2002, Engelhard \& Heino 2004). While the earlier studies have provided support of the compensatory response hypothesis put forward to explain the maturity changes, they have left the possibility of an evolutionary response open (Engelhard \& Heino 2004). The present paper disentangles for the first time these 2 non-exclusive hypotheses. The results suggest a strong compensatory and a possible weak evolutionary response.

\section{Evidence of 'compensatory response' hypothesis}

The compensatory response hypothesis predicts that a decline in stock size, by reducing intraspecific competition for food, will lead to faster growth rates and therefore earlier maturity as a phenotypically plastic response. The observation that growth rates for the Norwegian spring-spawning herring have mirrored stock size fluctuations supports this hypothesis (Tore- 
sen 1990b, Engelhard \& Heino 2004). In particular, the weak year-classes 1969 to 1982 showed considerably higher growth rates and earlier maturity than both earlier and later year-classes (Engelhard \& Heino 2004).

Year-class strength appears to be the main factor explaining trends in growth rates. In general, growth of Norwegian spring-spawning herring is negatively affected by year-class strength, due to 2 mechanisms (Toresen 1990a). First, juveniles of weak year-classes are typically geographically restricted to the temperate coastal waters and fjords of Norway; those of strong year-classes are, in addition, distributed widely in the colder Atlantic water masses of the Barents Sea, where the growth rates are slower. Second, the density of herring in the fjords is higher when the year-class is rich than when it is weak, leading to density-dependent growth. Analogously, in the period following collapse, juvenile herring were extremely rare in the Barents sea and were almost confined to the warmer fjord waters (Dragesund et al. 1997, Holst $\&$ Slotte 1998).

Our result, that maturation reaction norms have remained relatively stable, suggests that changes in maturation tendency have contributed relatively little to the observed, drastic changes in the maturity of Norwegian spring-spawning herring. This result, together with the observed covariance of maturity and growth (Toresen 1990b, Engelhard \& Heino 2004), provides strong evidence for the compensatory response hypothesis. Such evidence per se is, however, not sufficient enough to reject the evolutionary response hypothesis, as the 2 hypotheses are not mutually exclusive.

\section{Evidence of 'evolutionary response' hypothesis}

The evolutionary response hypothesis predicts that maturity changes are (at least partly) due to a genetic change in maturation properties, resulting from fisheries-induced selection pressures (Law \& Grey 1989, Law 2000, Heino et al. 2002a,b). Such an evolutionary change will be measurable as a change in the age and size-dependent tendency of immature individuals to commence reproducing (Heino et al. 2002a,b).

This study shows that a statistically significant, but quantitatively small, change in the reaction norm for age and length at maturation has occurred in the Norwegian spring-spawning herring stock. This is illustrated by a comparison of the 'historic' with the 'contemporary' reaction norm (Fig. 3): for the Ages 5 and 6 years, small but significant changes in the reaction norm were detected between the 2 periods (Table 2 ). For these 2 ages, the existence of a temporal trend in the reaction norm was confirmed by an analysis of the entire time-series of the year-classes 1930 to 1992 (Fig. 4). These changes accounted for $~ 3 \%$ decrease in reaction norm midpoints over a $62 \mathrm{yr}$ period, demonstrated for 2 maturation ages ( 5 and 6 yr) but not for the other maturation ages $(3,4,7$ and $8 \mathrm{yr})$. The results are thus compatible with a small evolutionary change towards earlier maturation.

The biological relevance of the documented changes in reaction norms could be questioned. First, the very high sample sizes (see Table 1) and the resultant high statistical power of the analyses allow detection of very small effects. Second, the apparent tilt in the contemporary reaction norm (Fig. 3b) is largely caused by the inaccurately known midpoint for Age 7, which is based on only 3 year-classes and is not significantly different from the historic midpoint for that age (Table 2). Third, the statistical hypothesis testing assumes that the source data are unbiased and that the model is 'correct'. If the degree of violation of model assumptions or biases in the source data shows a temporal trend, then statistical analyses may suggest spurious trends.

Furthermore, even when the changes in the maturation reaction norm are real, the interpretation of such changes as evidence of evolutionary change might still be challenged. Such an interpretation assumes that the phenotypic plasticity in maturation can be captured by length and age only. In reality other factors may also be important, and changes in those factors may cause plastic changes in maturation. Such potentially confounding factors may generally include body condition or energy stores (Rowe \& Thorpe 1990, Silverstein et al. 1997, Shearer \& Swanson 2000, Grift et al. 2003), maternal effects (Heath et al. 1994, Silverstein et al. 1997), and growth rate (Silverstein et al. 1998) - note though that the combination of length and age is a measure of average lifetime growth rate. Importantly, the condition factor in the Norwegian spring-spawning herring stock was somewhat lower in the 1930s and early 1940s than in most later years (Holst 1996). At the same length and age, immature fish with higher body weight are likely to have higher maturation probabilities. The bettered condition of the herring could thus explain the changes in the maturation reaction norm, especially given that the changes are so small. Evaluating the importance of this effect would require further analyses.

We consider it unlikely that the changes in reaction norms were due to gene flow from adjacent herring stocks. Norwegian spring-spawning herring vastly outnumber the small fjord-inhabiting herring stocks, and are furthermore easily distinguishable from fjord herring by their larger body size. In the southernmost parts of their range, Norwegian spring-spawning herring can co-occur with North Sea autumn-spawn- 
ing herring. Because of their different spawning times, however, the samples of mature herring collected from the spawning grounds are unlikely to contain more than sporadic specimens of North Sea herring. In the 1970s, when Norwegian spring-spawning herring were severely depleted, so were the North Sea herring (Nicholls 2001).

Overall, our results suggest that, by far, most of the changes in maturity-at-age and maturity-at-length in Norwegian spring-spawning herring, coinciding with abundance fluctuations, were due to a strong phenotypically plastic response to the growth rates. The quantitatively small change in maturation reaction norms provides some support for a small genetic change in maturation tendencies, but this interpretation remains ambiguous.

\section{Comparison with other stocks: biological properties}

Reaction norm analyses have recently been carried out in order to disentangle phenotypic and evolutionary changes in maturation for several other commercially exploited fish stocks that have shown considerable maturity changes. These include 4 stocks of Atlantic cod-Northeast Arctic cod: Heino et al. (2002c); Gulf of Maine and Georges Bank cod: Barot et al. (in press); northern (Newfoundland) cod: Olsen et al. (2004) - and the North Sea plaice stock (Grift et al. 2003). For each of these stocks, marked changes in maturation reaction norms, indicative of fisheriesinduced evolutionary change, were found. By contrast, for the Norwegian spring-spawning herring stock, the present study shows that no strong change in maturation tendencies has occurred, although the possibility of small-scale changes in reaction norms cannot be excluded. This is remarkable given the severity of the collapse of this stock and in particular, the extremely high fishing mortality rates in the overexploitation period (Fig. 1).

What factors might account for the weak evolutionary response to exploitation pressure in Norwegian spring-spawning herring compared to the other stocks investigated? Is there simply a lack of genetic variation for maturation in this stock? This would be surprising, given that life-history traits generally have moderate heritabilities (Mousseau \& Roff 1987). Alternatively, recent modelling work by Ernande et al. (2004) has shown that, under the influence of a given fisheriesinduced selection pressure, the shift in the maturation reaction norm will depend on certain biological properties of a fish stock. Harvesting mortality being fixed, the sensitivity of the evolutionary response is predicted to decrease (Ernande et al. 2004) if (1) the average natural mortality increases at ages potentially relevant for maturation (implying a small additive effect of fishing mortality), (2) the average growth rate decreases (implying less variability in size where selection may act upon), and (3) the trade-off between growth and reproduction is stronger (implying that earlier maturation causes a strong reduction in offspring produced at later reproductive events).

The Norwegian spring-spawning herring stock is characterised by just 1 of these 3 properties. Indeed, the trade-off between growth and reproduction is strong in this stock, as evidenced by a clear decrease in growth after maturation (Runnström 1936, Engelhard et al. 2003) that is more marked than in North Sea plaice (Rijnsdorp \& Storbeck 1995) and far more marked than in Northeast Arctic and Georges Bank cod (Law \& Grey 1989, Trippel et al. 1995) - all stocks where evolutionary responses to harvesting have been recorded (Heino et al. 2002c, Grift et al. 2003, Barot et al. in press). However, the average growth rates in herring are not particularly slow; they lie below those for cod, which attain larger body sizes, but are comparable to those in the North Sea plaice stock, which exhibited fisheries-induced adaptive change (Grift et al. 2003). Of theoretically highest relevance, although in general poorly known, natural mortality in Norwegian spring-spawning herring is probably comparable to that in the other stocks: the value assumed in stock assessments ( $M=0.15 \mathrm{yr}^{-1}$; ICES 2002) is intermediate in that it is between those for Northeast Arctic $\operatorname{cod}(M=$ $0.2 \mathrm{yr}^{-1}$; ICES 2003) and North Sea plaice $\left(M=0.1 \mathrm{yr}^{-1}\right.$; Beverton 1964). The specific biological properties of Norwegian spring-spawning herring might therefore only to some extent explain the apparent absence of a clear adaptive response of the stock to exploitation pressures.

\section{Comparison with other stocks: fishing patterns}

The various evolutionary responses among fish stocks might also be explained by differences in the intensity and pattern of the fisheries imposed on them, rather than in properties of the exploited stocks themselves (cf. Law \& Grey 1989, Law 2000). First, in Norwegian spring-spawning herring, high exploitation levels may not have persisted over a sufficient number of generations to cause genetic change: the fishing mortality in this stock had been low for a very long time and then rather suddenly increased to very high levels but for a relatively short period of just over 2 decades (Fig. 1). Still, in the case of northern cod, which has a similar generation time, 2 decades of intensive exploitation were apparently sufficient to cause a drastic change in the maturation reaction norm (Olsen et al. 2004). 
Secondly, apart from fishing intensity, it is likely that the pattern of fishing is also of high relevance regarding the potential of evolutionary change in a stock. Strong selection for earlier maturation is to be expected, in particular if a fishery targets both mature and immature fish simultaneously (Law \& Grey 1989, Heino 1998, Ernande et al. 2004): early-maturing individuals then have a strong fitness advantage, since delayed maturation implies a strong risk of dying without offspring. The same applies to selective harvesting of immature fish only (Ernande et al. 2004). However, relatively weaker selection for later maturation is to be expected in the case of a fishery specifically targeting mature fish (Law \& Grey 1989, Heino 1998, Ernande et al. 2004).

The first of these 3 fishing patterns has been the case in the above-mentioned cod and plaice stocks where clearly decreasing reaction norms were found (Heino et al. 2002c, Grift et al. 2003, Barot et al. in press). These stocks have been subjected to significant harvesting at feeding areas where mature and immature fish, of various ages and sizes, forage together in mixed shoals. In contrast, the lastmentioned fishing pattern has been prevailing in the case of Norwegian spring-spawning herring, due to the strong spatio-temporal segregation of immature and mature herring. Since ancient times, the winter and spring herring fisheries occurring at the spawning grounds (and more recently in the overwintering area) have targeted schools of spawning or prespawning, i.e. mature fish. For many decades the summer herring fisheries targeted schools of feeding herring in the Norwegian Sea that consisted, for the most part, of mature fish. In addition, in the decades before stock collapse, the small herring and fat herring fisheries operating in the nursery areas targeted small juvenile fish of ages and sizes not yet relevant for maturation (Toresen \& Østvedt 2000, Toresen \& Jakobsson 2002). Theoretically, the evolutionary consequences of harvesting fish of ages and sizes well below those physiologically required for maturation are not properly known. However, as advancing or delaying maturation would not have a direct effect on the likelihood of an individual being fished, it is safe to assume that selection pressures on maturation would be relatively weak. Thus, we conclude that even though the fishing mortality in Norwegian spring-spawning herring was extremely high in the overexploitation period, selection pressures on maturation reaction norms have probably been moderate.

What if the small change in maturation reaction norms of Norwegian spring-spawning herring indeed represents a genetic change in maturation tendency? On the basis of what is known about herring fisheries, advanced maturation is at odds on the selection pres- sures that would theoretically be expected. An intriguing possibility is that old immature herring in the Norwegian Sea may have been subject to larger fishing pressure than generally believed. Unfortunately, a closer study of this hypothesis is difficult, as mature and immature herring are not separated in the catch statistics.

\section{Perspectives}

Large changes in maturity are taking place in many fish stocks, and the causes of these are often unclear (Browman 2000, Law 2000). Since age and size at maturation are important production-related traits, it is important to understand the nature of maturity changes. To what extent do these only represent phenotypic responses to environmental change (and probably readily reversible to the original situation if conditions do as well), or are these really evolutionary responses to directional selection caused by fishing (and probably difficult to reverse)? For several fish stocks of major commercial significance, analyses of maturation reaction norms (Heino et al. 2002a,b) have now shed some light on this controversial issue. The less promising picture of significant fisheries-induced evolutionary change appears true for the 5 earlier examined stocks (Heino et al. 2002c, Grift et al. 2003, Barot et al. in press, Olsen et al. 2004), implying lower yields per fish caught (Law \& Grey 1989, Hutchings 1993, Stokes \& Law 2000). Norwegian spring-spawning herring apparently forms an exception, as it shows only a marginal change in its maturation reaction norm. The findings provide empirical evidence for Law \& Grey's (1989) prediction that a fishery targeting both mature and immature fish simultaneously is more likely to cause evolutionary change in maturation tendencies than a fishery targeting only mature fish. Maintaining the latter pattern of fishing with Norwegian spring-spawning herring may be desirable over the former if the possible evolutionary degradation of a productivity-related life-history trait were to be avoided-a consideration highly relevant for the sustainable management of fish stocks (Policansky 1993, Heino 1998, Browman 2000, Hutchings 2000, Law 2000).

Acknowledgements. We thank U. Dieckmann, B. Ernande, O. R. Godø, E. Olsen, A. Slotte and T. Van Dooren for their valuable help, discussions and comments. The paper has benefited from the comments by 3 anonymous reviewers. This research has been supported by the European Research Training Network ModLife (Modern Life-History Theory and its Application to the Management of Natural Resources), funded through the Human Potential Programme of the European Commission (Contract HPRN-CT-2000-00051). 


\section{LITERATURE CITED}

Barot S, Heino M, O'Brien L, Dieckmann U (in press) Reaction norms for age and size at maturation: study of the longterm trend (1970-1998) for Georges Bank and Gulf of Maine cod stocks. Ecol Appl

Bernardo J (1993) Determinants of maturation in animals. Trends Ecol Evol 8:166-173

Beverton RJH (1964) Differential catchability of male and female plaice in the North Sea and its effect on estimates of stock abundance. Rapp p-v Reun Cons Int Explor Mer 155:103-112

Borisov VM (1978) The selective effect of fishing on the population structure of species with a long life cycle. J Ichthyol 18:896-904

Bromley PJ (2000) Growth, sexual maturity and spawning in central North Sea plaice (Pleuronectes platessa L.), and the generation of maturity ogives from commercial catch data. J Sea Res 44:27-43

Browman HI (2000) Application of evolutionary theory to fisheries science and stock assessment-management. Mar Ecol Prog Ser 208:299

Christensen V, Guénette S, Heymans JJ, Walters CJ, Watson R, Zeller D, Pauly D (2003) Hundred-year decline of North Atlantic predatory fishes. Fish Fish Ser 4:1-24

Conover DO, Munch SB (2002) Sustaining fisheries yields over evolutionary time scales. Science 297:94-96

Corten A (2001) Herring and climate: changes in the distribution of North Sea herring due to climatic conditions. PhD thesis, University of Groningen, Groningen

Dragesund O, Ulltang $\varnothing$ (1978) Stock size fluctuations and rate of exploitation of the Norwegian spring spawning herring, 1950-1974. FiskDir Skr Ser Havunders 16: 315-337

Dragesund O, Johannesen A, Ulltang Ø (1997) Variation in migration and abundance of Norwegian spring spawning herring (Clupea harengus L.). Sarsia 82:97-105

Engelhard GH, Heino M (2004) Maturity changes in Norwegian spring-spawning herring before, during, and after a major population collapse. Fish Res 66:299-310

Engelhard GH, Dieckmann U, Godø OR (2003) Age at maturation predicted from routine scale measurements in Norwegian spring-spawning herring (Clupea harengus) using discriminant and neural network analyses. ICES J Mar Sci 60:304-313

Ernande B, Dieckmann U, Heino M (2004) Adaptive changes in harvested populations: plasticity and evolution of age and size at maturation. Proc R Soc Lond B 271:415-423

Francis RICC (1990) Back-calculation of fish length: a critical review. J Fish Biol 36:883-902

Grift RE, Rijnsdorp AD, Barot S, Heino M, Dieckmann U (2003) Fisheries-induced trends in reaction norms for maturation in North Sea plaice. Mar Ecol Prog Ser 257: $247-257$

Gulland JA (1964) The abundance of fish stocks in the Barents Sea. Rapp p-v Reun Cons Int Explor Mer 155:126-137

Haug T, Tjemsland J (1986) Changes in size- and age-distributions and age at sexual maturity in Atlantic halibut, Hippoglossus hippoglossus, caught in Norwegian waters. Fish Res 4:145-155

Heath DD, Devlin RH, Heath JW, Iwama GK (1994) Genetic, environmental and interaction effects on the incidence of jacking in Oncorhynchus tshawytscha (chinook salmon). Heredity 72:146-154

Heino M (1998) Management of evolving fish stocks. Can J Fish Aquat Sci 55:1971-1982

Heino M, Godø OR (2002) Fisheries-induced selection pressures in the context of sustainable fisheries. Bull Mar Sci 70:639-656

Heino M, Dieckmann U, Godø OR (2002a) Measuring probabilistic reaction norms for age and size at maturation. Evolution 56:669-678

Heino M, Dieckmann U, Godø OR (2002b) Estimation of reaction norms for age and size at maturation with reconstructed immature size distributions: a new technique illustrated by application to the Northeast Arctic cod. ICES J Mar Sci 59:562-575

Heino M, Dieckmann U, Godø OR (2002c) Reaction norm analysis of fisheries-induced adaptive change and the case of the Northeast Arctic cod. ICES CM 2002/Y:14

Holst JC (1996) Long term trends in the growth and recruitment pattern of the Norwegian spring-spawning herring (Clupea harengus Linnaeus 1758). PhD thesis, University of Bergen, Norway

Holst JC, Slotte A (1998) Effects of juvenile nursery on geographic spawning distribution in Norwegian springspawning herring (Clupea harengus L.). ICES J Mar Sci 55:987-996

Hutchings JA (1993) Reaction norms for reproductive traits in brook trout and their influence on life history evolution affected by size-selective harvesting. In: Stokes TK, McGlade JM, Law R (eds) The exploitation of evolving resources. Springer-Verlag, Berlin, p 107-125

Hutchings JA (2000) Numerical assessment in the front seat, ecology and evolution in the back seat: time to change drivers in fisheries and aquatic sciences? Mar Ecol Prog Ser 208:299-303

ICES (2002) Report of the Northern Pelagic and Blue Whiting Fisheries Working Group, Vigo, Spain, 29 April-8 May 2002. ICES CM 2002/ACFM:19

ICES (2003) Report of the Arctic Fisheries Working Group, San Sebastian, Spain, 23 April-2 May 2003. ICES CM 2003/ACFM:22

Jørgensen T (1990) Long-term changes in age at sexual maturity of Northeast Arctic cod (Gadus morhua L.). J Cons Int Explor Mer 46:235-248

Law R (2000) Fishing, selection, and phenotypic evolution. ICES J Mar Sci 57:659-668

Law R, Grey DR (1989) Evolution of yields from populations with age-specific cropping. Evol Ecol 3:343-359

Marshall CT, Kjesbu OS, Yaragina NA, Solemdal P, Ulltang $\varnothing$ (1998) Is spawner biomass a sensitive measure of the reproductive and recruitment potential of Northeast Arctic cod? Can J Fish Aquat Sci 55:1766-1783

Mousseau TA, Roff DA (1987) Natural selection and the heritability of fitness components. Heredity 59:181-197

Murawski SA, Rago PJ, Trippel EA (2001) Impacts of demographic variation in spawning characteristics on reference points for fishery management. ICES J Mar Sci 58: 1002-1014

Myers RA, Worm B (2003) Rapid worldwide depletion of predatory fish communities. Nature 423:280-283

Nicholls JH (2001) Management of North Sea herring and prospects for a new millennium. In: Funk F, Blackburn J, Hay D, Paul AJ, Stephenson R, Toresen R, Witherell D (eds) Herring: expectations for a new millennium. University of Alaska Sea Grant AK-SG-01-04, Fairbanks, AK, p 645-665

O'Brien L (1999) Factors influencing the rate of sexual maturity and the effect on spawning stock for Georges Bank and Gulf of Maine Atlantic cod Gadus morhua stocks. J Northwest Atl Fish Sci 25:179-203

Olsen EM, Heino M, Lilly GR, Morgan MJ, Brattey J, Ernande B, Dieckmann U (2004) Maturation trends indicative of 
rapid evolution preceded the collapse of northern cod. Nature 428:932-935

Policansky D (1993) Fishing as a cause of evolution in fishes. In: Stokes TK, McGlade JM, Law R (eds) The exploitation of evolving resources. Springer-Verlag, Berlin, p 2-18

Rijnsdorp AD (1993) Fisheries as a large-scale experiment on life-history evolution: disentangling phenotypic and genetic effects in changes at maturation and reproduction of North Sea plaice, Pleuronectes platessa L. Oecologia 96: 391-401

Rijnsdorp AD, Storbeck F (1995) Determining the onset of sexual maturity from otoliths of individual female North Sea plaice, Pleuronectes platessa L. In: Secor D, Dean JM, Campana S (ed) Recent developments in fish otolith research. University of South Carolina Press, Columbia, SC, p 581-598

Rowe DK, Thorpe JE (1990) Differences in growth between maturing and non-maturing male Atlantic salmon, Salmo salar L., parr. J Fish Biol 36:643-658

Runnström S (1936) A study on the life history and migrations of the Norwegian spring-herring based on the analysis of the winter rings and summer zones of the scale. FiskDir Skr Ser Havunders 5(2):1-103

Shearer KD, Swanson P (2000) The effect of whole body lipid on early sexual maturation of $1+$ age male chinook salmon (Oncorhynchus tshawytscha). Aquaculture 190:343-367

Silverstein JT, Shimma O, Ogata H (1997) Early maturity in amago salmon (Oncorhynchus masu ishikawai): an association with energy storage. Can J Fish Aquat Sci 54: $444-451$

Silverstein JT, Shearer KD, Dickhoff WW, Plisetskaya EM (1998) Effects of growth and fatness on sexual development of chinook salmon (Oncorhynchus tshawytscha) parr. Can J Fish Aquat Sci 55:2376-2382

Editorial responsibility: Howard Browman (Contributing Editor), Storebø, Norway
Stearns SC (1992) The evolution of life histories. Oxford University Press, New York

Stearns SC, Koella JC (1986) The evolution of phenotypic plasticity in life-history traits: predictions of reaction norms for age and size at maturity. Evolution 40:893-913

Stokes K, Law R (2000) Fishing as an evolutionary force. Mar Ecol Prog Ser 208:307-309

Toresen R (1990a) Long-term changes in growth of Norwegian spring-spawning herring. J Cons Int Explor Mer $47: 48-56$

Toresen R (1990b) Long-term changes of growth and maturation in the Norwegian spring spawning herring. In: Monstad $\mathrm{T}$ (ed) Biology and fisheries of the Norwegian spring spawning herring and blue whiting in the Northeast Atlantic. Institute of Marine Research, Bergen, Norway, p 89-106

Toresen R, Jakobsson J (2002) Exploitation and management of Norwegian spring-spawning herring in the 20th century. ICES Mar Sci Symp 215:558-571

Toresen R, Østvedt OJ (2000) Variation in abundance of Norwegian spring-spawning herring (Clupea harengus, Clupeidae) throughout the 20th century and the influence of climatic conditions. Fish Fish Ser 1:231-256

Toresen R, Østvedt OJ (2002) Stock structure of Norwegian spring-spawning herring: historical background and recent apprehension. ICES Mar Sci Symp 215:532-542

Trippel EA (1995) Age at maturity as a stress indicator in fisheries. BioScience 45:759-771

Trippel EA, Buzeta M-I, Hunt JJ (1995) Evaluation of the cost of reproduction in Georges Bank Atlantic cod (Gadus morhua): utility of otolith back-calculation. In: Secor D, Dean JM, Campana S (eds) Recent developments in fish otolith research. University of South Carolina Press, Columbia, SC, p 599-616

Submitted: September 16, 2003; Accepted: December 1, 2003 Proofs received from author(s): May 12, 2004 